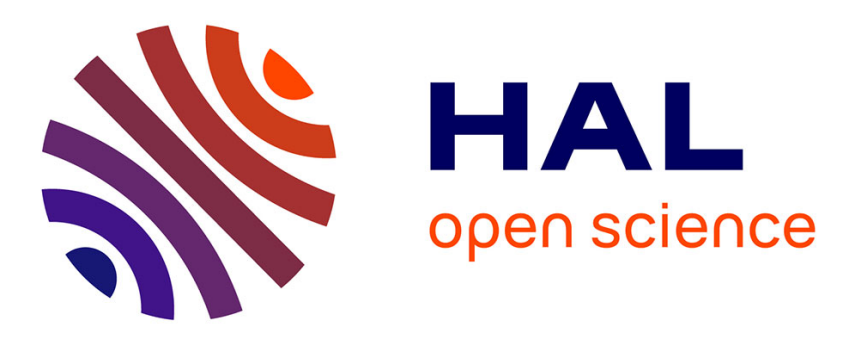

\title{
Study of synergetic effect by surface discharge plasma/TiO2 combination for indoor air treatment: sequential and continuous configurations at pilot scale
}

Aymen Amine Assadi, Abdelkrim Bouzaza, Dominique Wolbert

\section{- To cite this version:}

Aymen Amine Assadi, Abdelkrim Bouzaza, Dominique Wolbert. Study of synergetic effect by surface discharge plasma/ $\mathrm{TiO} 2$ combination for indoor air treatment: sequential and continuous configurations at pilot scale. Journal of Photochemistry and Photobiology A: Chemistry, 2015, 310, pp.148-154. 10.1016/j.jphotochem.2015.05.007 . hal-01158449

HAL Id: hal-01158449

https://hal-univ-rennes1.archives-ouvertes.fr/hal-01158449

Submitted on 12 Nov 2015

HAL is a multi-disciplinary open access archive for the deposit and dissemination of scientific research documents, whether they are published or not. The documents may come from teaching and research institutions in France or abroad, or from public or private research centers.
L'archive ouverte pluridisciplinaire $\mathbf{H A L}$, est destinée au dépôt et à la diffusion de documents scientifiques de niveau recherche, publiés ou non, émanant des établissements d'enseignement et de recherche français ou étrangers, des laboratoires publics ou privés. 


\title{
Study of synergetic effect by surface discharge plasma/TiO $\mathrm{T}_{2}$ combination for indoor air treatment: sequential and continuous configurations at pilot scale
}

\author{
ASSADI Aymen Amine ${ }^{\text {a.b* }}$, BOUZAZA Abdelkrim a,b, WOLBERT Dominique a,b, \\ ${ }^{a}$ Laboratoire Sciences Chimiques de Rennes - équipe Chimie et Ingénierie des Procédés, UMR 6226 \\ CNRS, ENSCR-11, allée de Beaulieu, CS 508307-35708 Rennes, France. \\ ${ }^{\mathrm{b}}$ Université Européenne de Bretagne, Rennes-France \\ * Corresponding author. Tel.: +33 2 23238056; fax: +33 223238120 . \\ E-mail address: Aymen.assadi@ensc-rennes.fr (A. A. ASSADI).
}

\section{Graphical abstract}

Sequential and continuous configurations at pilot scale.

\section{Highlights}

- Butyraldehyde removal by plasma and photocatalysis is studied at pilot scale.

- Effects of some operating parameters on performance of each process are tested.

- A synergetic effect is confirmed by plasma DBD and photocatalysis combined.

- Sequential and continuous configurations have been investigated

- Possible reasons of synergetic effect have been discussed

Abstract

This work investigated the performance of butyraldehyde decomposition with the help of dielectric barrier discharge (DBD) plasma coupled with photocatalysis $\left(\mathrm{TiO}_{2}+\mathrm{UV}\right)$ at room 
temperature. Effects of flow rate and initial butyraldehyde concentration on the decomposition and the distribution of byproducts were examined and discussed. The combination of these two technologies led to an enhancement of butyraldehyde abatement compared to the separate systems at pilot scale from 5 to $10 \mathrm{~m}^{3} \cdot \mathrm{h}^{-1}$ of flowrate. The synergy factor due to combination processes ranged from 1.13 to 1.27 . In the same way, $\mathrm{CO}_{2}$ selectivity was significantly improved when compared to the DBD plasma alone. In this research, DBD plasma system and an immobilized $\mathrm{TiO}_{2}$ photocatalysis system is sequentially combined to oxidize the target pollutant. Indeed, different ways to combine sequentially DBD plasma with photocatalytic materials are listed. Results at pilot scale showed that when photocatalyst is placed in the post discharge, the performance of sequential coupling plasmaphotocatalyst process is improved in term of decomposition, by-products formation and energy yield.

Keywords: Pilot scale, Sequential coupling processes, DBD plasma, photocatalysis, synergetic effect

\section{Introduction}

Air pollution has become a global issue that endangers the condition of the environment and poses serious health risks [1]. In this regard, volatile organic compounds (VOCs) are one of the most common precursors of atmospheric pollution, and present adverse effects on the environment and human health [2]. Consequently, considerable attention has been paid to develop methods for removing these VOCs [3]. In recent years, non-thermal plasma (NTP) has emerged as a promising method for decomposing VOCs [4-6]. Non-thermal plasmas generated by dielectric barrier discharge provide high-energy electrons capable of generating ions, radicals and excited particles which can react with pollution in air [7]. In such systems, adding catalyst in plasma zone can improve the efficiency of VOCs removal and $\mathrm{CO}_{2}$ formation. Generally, a synergetic effect on the removal efficiency of VOCs has been reported $[10,12,18]$. Indeed, photocatalysts are semiconductors activated by photons which create electron-hole pairs, inducing oxidation or reduction reactions at the surface of the material with adsorbed molecules $[\mathbf{8}, \mathbf{9}]$. $\mathrm{TiO}_{2}$ activated by UV radiation is one of the most efficient photocatalysts for VOCs treatment. However, at lab scale, Thevenet et al [12] pointed out that, UV light due to surface plasma discharge was very weak to activate the $\mathrm{TiO}_{2}$. Assadi et al [11] observed same behavior at pilot scale. So its contribution to the 
removal of VOC in plasma $\mathrm{DBD} /$ photocatalysis combination reactor could be ignored. Thus, external UV light is necessary to activate the photocatalyst media $[\mathbf{1 2}, \mathbf{1 8}]$.

On the other hand, there are little investigations on configurations of placing catalyst in discharge zone. In fact, some studies about two configurations referred to as in-plasma catalysis (IPC) and post plasma catalysis (PPC) are tested [4, 13]. Thus, performances of sequential coupling processes are not well understood yet.

The aim of this study was to extend previous research [11-13] by adding an investigation about sequential combined plasma/photocatalysis process at pilot scale. Indeed, the aim of this study was to try to combine the advantages of photocatalysis and surface discharge plasma by combining the two technologies in the same reactor which should be able to treat larger flowrate than the laboratory reactors usually used. On other way, a special attention is given to the effect of photocatalyst position and its effect on the ozone decomposition, which is innovative in comparison to latter studies. Here, butyraldehyde (BUTY) was chosen as the target compound because it is one of the frequently encountered organic compounds in indoor environments [14]. Furthermore, BUTY is listed as one of the surrogates for the six major classes of indoor VOCs (aromatic, aldehyde, alkane, ketone, alcohol and chlorocarbon) by the French Environment and Energy Management Agency (ADEME) [15].

\section{Experimental}

The used experimental setup is structured alike: (i) gas flow preparation, (ii) plasma set up, (iii) photocatalysis set up and (iv) analysis.

\subsection{Gas flow preparation}

The ambient air is the gas carrier. The air stream is generated by a fan. A flow meter (Bronkhorst IN-FLOW) allows the flow rate to be controlled. In order to keep constant the relative humidity of the gas $(\sim 50 \%)$, a variable part of the air flow is derived through a packed column where water flows in counter current. BUTY is injected continuously in liquid form by a syringe/syringe driver combination. To facilitate its volatilization, a heating tape, is placed upstream to the injection zone. In other hand, a static mixer allows the effluent upstream to the reactor to be homogenized. The temperature in the reactor is $20^{\circ} \mathrm{C}$. Two septa downstream and upstream of the reactor allows outlet and inlet gas to be sampled with a 100 $\mu \mathrm{L}$ syringe (Fig. 1). 


\section{Fig 1: Experimental set-up}

\subsection{Plasma set up}

The experiments were carried out at ambient conditions i.e. room temperature and pressure. The used reactor had been described in detail in our previous work [6]. Briefly, the reactor consists of a rectangular cross section and it contains two plates. A $2 \mathrm{~mm}$ thickness grid with wire electrodes shaped as a rectangle. The distance between two wire electrodes was $20 \mathrm{~mm}$. The used inside material is $4 \mathrm{~L}$ glass. The air flows tangentially over the photocatalyst medium or/and plasma with a flow rates varying from 5 to $10 \mathrm{~m}^{3} \mathrm{~h}^{-1}$ which correspond to gas residence times inside the photocatalytic section ranging from 1.25 to $2.5 \mathrm{~s}$.

The outer electrode, connected to the ground, is a $1 \mathrm{~mm}$ thick and $80 \mathrm{~cm}$ length copper foil. The electrodes were attached around the glass plate with $4 \mathrm{~mm}$ thickness.

The DBD plasma was obtained by submitting the electrodes to a sinusoidal high voltage ranging from 0 to $21 \mathrm{kV}$ at a $50 \mathrm{~Hz}$ frequency using amplifier TREK 30A/40. A $2.5 \mathrm{nF}$ capacitance was positioned between the outer electrode and the ground connection in order to collect the charges transferred through the reactor (Manley's method [16]). Charge and voltage are recorded with a $200 \mathrm{MHz}$ bandwidth (maximum $1 \mathrm{GS} / \mathrm{s}$ ) oscilloscope (LeCroy, $200 \mathrm{MHz})$.

\subsection{Photocatalysis set up}

The same reactor was used to investigate the photocatalytic experiments. In fact, eight UV lamps are placed in air gap of the reactor and the photocatalysis media is maintained between the plate and the inner electrode in order to ensure a good radiation distribution. The emission spectrum of the lamps (Philips under reference PL-S 9W/10/4P, $0.012 \mathrm{~m}$ bulb diameter, 0.135 $\mathrm{m}$ bulb length) is centered at $365 \mathrm{~nm}$. The UV photonic flux on the photocatalyst surface ranges from 38 to $40 \mathrm{~W} \cdot \mathrm{m}^{-2}$. The photocatalytic media which has been largely described in previous studies [11] is a fiber glass mat coated with $20 \mathrm{~g} . \mathrm{m}^{-2}$ of colloidal silica to ensure the fixation of $20 \mathrm{~g} . \mathrm{m}^{-2}$ of PC500 Millenium titanium dioxide nanoparticles.

\subsection{Analysis system}


The details of the analysis system were given elsewhere [12]. Briefly, gas samples of BUTY were taken with an airtight syringe and injected into gas phase chromatograph (Fisons GC9000) equipped with a flame ionization detector (FID). Separations of BUTY and by-products were performed by a Chrompact FFAP-CB column (25 m of length $0.32 \mathrm{~mm}$ of external diameter $0.32 \mathrm{~mm}$ ), which was specially adapted for VFAs (Volatile Fatty Acids), and nitrogen gas as the mobile phase. The temperature conditions in the oven, the injection chamber and the detector were, respectively, 100,120 and $200{ }^{\circ} \mathrm{C}$.

All injections were performed manually and repeated three times with a syringe of 500 $\mu$ l. $\mathrm{CO}_{2}$ was analyzed by a Fourier Transform Infrared (FTIR) spectrophotometer brand Environnement SA (Cosma Beryl reference 100). NOx and CO concentrations were measured by NO/CO ZRE gas analyzer. A standard iodometric titration method was used to estimate the formation of the downstream ozone. Temperature and relative humidity were measured with a TESTO 445 probe.

\subsection{Experimental procedure}

Preliminary step is the air stream conditioning: temperature, flow rate and humidity. Then the pollutant is injected continuously at specific rate to reach the desired inlet concentration.

Seven kinds of experiments have been carried out in order to understand the interaction between DBD plasma and photocatalytic material at pilot scale. Indeed, the following experiments are carried out:

- $100 \%$ Photocatalysis $\left(\mathrm{TiO}_{2}+\mathbf{U V}\right): \mathrm{TiO}_{2}$ photocatalytic material is placed inside the reactor. The UV lamp is on, no voltage is applied.

- $100 \%$ DBD Plasma alone: DBD plasma is the only oxidative process performed. No photocatalyst and no UV lamp

- $100 \%$ Coupled process: High voltage and the UV lamp are on with the presence of photocatalysis inside reactor

- 50 \% coupled process and $50 \%$ photocatalyst: High voltage and UV lamp are on with the presence of photocatalyst in the two parts of the reactor but DBD plasma was only performed on the first part (configuration I). The reverse order of technologies has been investigated on configuration II.

- 50 \% plasma and $50 \%$ combined process: DBD plasma is performed in the first part of the reactor while plasma and photocatalysis are implemented in the second 
part (configuration III). The reverse order of process succession has been tested also (configuration IV).

\section{Results and discussion}

Effects of several parameters, such as flowrate and inlet concentration on the BUTY removal were investigated.

The experiments, which were repeated two times, showed a good reproducibility with a $5 \%$ of averaged standard deviation. This averaged standard deviation is represented by vertical bars in all figures.

In order to evaluate the plasma, photocatalytic and combined (continuous or sequential) process performances, the following parameters are employed:

- BUTY removal efficiency (RE):

$$
R E(\%)=\frac{\left([B U T Y]_{\text {in }}-[B U T Y]_{\text {out }}\right)}{[B U T Y]_{\text {in }}} \times 100
$$

- Elimination capacity (EC):

$$
\mathrm{EC}\left(\mathrm{mg}, \mathbf{h}^{-1}\right)=\frac{R E(0) \times[B U T Y]_{i n} \times M \times Q}{100}
$$

where $[\mathrm{BUTY}]_{\text {in }}$ and $[\mathrm{BUTY}]_{\mathrm{out}}$ are respectively the inlet and outlet gas molar concentrations. $\mathrm{Q}$ is the flow rate and $\mathrm{M}$ is the molecular weight of BUTY.

- Selectivities of $\mathrm{CO}$ and $\mathrm{CO}_{2}$ :

$$
\begin{gathered}
S_{C O}(\%)=\frac{[C O]}{\left(4 \times[B U T Y]_{\text {conv }}\right)} \times 100 \\
S_{\mathrm{CO}_{2}}(\%)=\frac{\left[C \mathrm{C}_{2}\right]}{\left(4 \times[\text { BUTY }]_{\text {conv }}\right)} \times 100
\end{gathered}
$$


where $[\mathrm{CO}]$ and $\left[\mathrm{CO}_{2}\right]$ are respectively the molar concentrations of carbon monoxide and carbon dioxide detected in the effluent gas. [BUTY $]_{\text {conv }}$ is the molar concentration of BUTY converted. It can be evaluated by the following expression:

$$
[\mathrm{BUTY}]_{\text {onv }}=\frac{R E(0) \times[B U T Y]_{\text {in }}}{100}
$$

- Ozone concentration: Ozone is well known as an inevitable byproduct in a plasma process. It can be formed by the following reaction:

$$
\mathrm{O}^{\circ}+\mathrm{O}_{2}+\mathrm{M} \rightarrow \mathrm{O}_{3}+\mathrm{Z}
$$

where $\mathrm{O}^{\circ}$ atomic oxygen which was generated by $\mathrm{O}_{2}$ dissociation due to impact with high energy electrons. $Z$ can be either molecular oxygen or molecular nitrogen [17].

\subsection{Plasma, photocatalysis, combined system: continuous process}

\subsubsection{Abatement efficiency of BUTY at pilot scale}

Removal of BUTY was investigated in the planar reactor under various inlet concentrations and flow rates. The inlet concentrations of BUTY were 40 and $100 \mathrm{mg} \mathrm{m}^{-3}$. And the flow rates of effluent were 5 and $10 \mathrm{~m}^{3} \mathrm{~h}^{-1}$, which correspond to the residence time in the reactor of 2.5 and $1.25 \mathrm{~s}$ respectively.

Table 1 showed that these parameters were important factors that affect BUTY removal.

Table 1: EC values $\left(\mathrm{mg} \mathrm{h}^{-1}\right)$ for BUTY removal by DBD plasma, photocatalysis and a combined process at different flowrate and inlet concentration $\left(\mathrm{SE}=14 \mathrm{~J} \mathrm{~L}^{-1}, \mathrm{~T}=\mathbf{2 0}\right.$

$$
\left.{ }^{\circ} \mathrm{C}, \mathbf{I}=20 \mathrm{~W} \mathrm{~m}^{-2}\right) \text {. }
$$

With plasma, photocatalysis and combined process, the elimination capacities of BUTY increase with an increase in the initial concentration. Indeed, using plasma alone and at flowrate equal to $5 \mathrm{~m}^{3} \mathrm{~h}^{-1}$ the $\mathrm{EC}$ at 40 and $100 \mathrm{mg} \mathrm{m}^{-3}$ were 42.86 and $80.35 \mathrm{mg} \mathrm{h}^{-1}$, respectively. Previous studies at laboratory scale have shown the same trend [5, 6, 11]. For diluted effluent, the EC is directly proportional to the inlet concentration. The elimination occurs to fit a first-order kinetic $[8, \mathbf{1 1}]$. At this specific concentration range, many reactive species remain available for the reaction. The same behavior can be observed with 
photocatalysis. It can be explained by the availability of the active sites for BUTY molecules $[13,18,19]$.

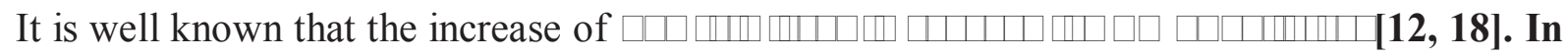
fact, the increase of the flow rate induces an important enhancement on EC with each process. This can be explained by the fact that the increase of air flow, is helpful to the transfer of BUTY molecules from bulk to discharge zone or photocatalytic zone $[\mathbf{6}, \mathbf{1 2}]$.

Indeed, in our previous study, we demonstrated that plasma can enhance the mass transfer step [21]. The behavior remains the same with plasma, photocatalysis and combined process in our cases. This result is similar to what has been observed in the literature, for example with isovaleraldehyde [30], toluene [5], Acetylene [8, 18], $\mathrm{H}_{2} \mathrm{~S}_{\text {and }} \mathrm{NH}_{3}[\mathbf{2 0}]$.

It is interesting to report that whatever the experimental conditions used, experimental results when plasma and photocatalysis are combined show a better elimination of BUTY than the simple addition of the two processes, revealing then an unambiguous synergy effect. Previous studies have shown that the combination of plasma discharge with heterogeneous catalysis often induces a synergetic effect on the removal efficiency $[8,10,12,13,18]$.

To evaluate the synergy, we introduce the term synergetic factor SF of BUTY elimination which is calculated as follow:

$$
\mathrm{SF}_{B U T Y}=\frac{(E C)_{\text {Combined }}}{(E C)_{\text {plasma }}+(E C)_{\text {photocatalysis }}}
$$

In fact, SF was between 1.13 and 1.27. This factor is similar to what has been observed in the literature, for example it was 1.1 with acetylene [8, 12], 1.20 with benzene [10] and 1.15 with $\mathrm{H}_{2} \mathrm{~S}[20]$.

\subsubsection{Byproducts formation}

It is well known that increasing the specific energy leads to increasing ozone concentration and selectivities of $\mathrm{CO}$ and $\mathrm{CO}_{2}[5,8,10,12,18]$. On the other hand, we report that whatever the process used (plasma, photocatalysis, combined process); the main reaction products are acetone, some alcohols (methanol and ethanol), carbon dioxide and carbon monoxide. 
Table 2 shows the $\mathrm{CO}_{2}$ selectivity and residual ozone concentration with plasma and photocatalysis and combined process at specific energy about $14 \mathrm{~J} \mathrm{~L}^{-1}$. We note that, with each tested process, the final concentration of NOx was lower than 4 ppmv

Each tested system show better performance in treating dilute BUTY. In fact, with plasma alone, the selectivity of $\mathrm{CO}_{2}$ for treating $100 \mathrm{mg} \mathrm{m}^{-3}$ of BUTY in air with flow rate of $4 \mathrm{~m}^{3} \mathrm{~h}^{-1}$ was $25 \%$, and increased to $38 \%$ for $40 \mathrm{mg} \mathrm{m}^{3}$. On the other hand, it is well known that the selectivities of COx decreases when gas flow rates expanded with each tested configuration [22]. Increasing the gas flow rate, namely decreasing the residence time in the reactor, caused that BUTY byproducts were submitted to a reducing number of plasma discharges and the probability of collision with electrons and subsequent radical reactions inhibit, which resulted in a lower mineralization $[\mathbf{2 3}, \mathbf{2 4}]$. One can note that with combined system the selectivity of $\mathrm{CO}_{2}$ was improved compared to plasma DBD alone whatever is the value of flowrate and inlet concentration. In fact by coupling these processes, $\mathrm{CO}_{2}$ selectivity is about $40 \%$, an intermediate value between photocatalysis and plasma alone. CO selectivity can be considered as negligible for plasma and combined system. Moreover, as mentioned in our previous study [12], with photocatalysis alone the final concentration of CO was lower than the detection limits of CO analyzer $(<0.05 \mathrm{ppmv})$.

As expected, it is well known that plasma produces ozone $[5, \mathbf{1 3}]$. First of all, the increase of flowrate leads to an increase of ozone concentration. In fact, the increase two times of the flowrate induces an increasing of $20 \%$ of formed ozone. On the other hand, the result shows that the amount of ozone was reduced when $\mathrm{TiO}_{2}$ catalyst is irradiated by UV. This behavior can be explained by the fact that UV irradiation is able to promote ozone elimination and it can also contribute to VOC elimination on the photocatalytic surface [13].

Table 2: $\mathrm{CO}_{2}$ Selectivity and residual ozone concentration at the exit of the reactor for different tested configurations (room temperature, input energy density $=14 \mathrm{~J} \mathrm{~L}^{-1}$ ).

On the other hand, experimental data for the plasma, photocatalysis and combined system are shown in Fig. 2. A linear relationship between $\mathrm{CO}_{2}$ selectivity and removal efficiency was obtained with plasma and photocatalysis reactors and no different behaviour between the processes was observed, which could indicate that no limitation is 
due to the actives species. In fact, as showed is Fig.2, when the removal efficiency increases, the $\mathrm{CO}_{2}$ selectivity increases also.

Fig. 2: Relationship between the selectivity of $\mathrm{CO}_{2}$ and the removal efficiency for the plasma, photocatalysis and combined system at different flowrates and inlet concentration.

\subsection{From continuous to sequential coupling processes using pilot scale}

Most of the published results describe continuous operating conditions; it means (i) that a constant amount of pollutant flows thro $\square$ h the plasma-photocatalyst reactor and (ii) that the discharge is permanently ignited. An alternative approach is to uncouple each process in order to distinguish plasma-photocatalytic effects on removal BUTY. The possible synergy could be discussed.

Therefore, four configurations have been carried out in order to better understand the plasmaphotocatalytic effects at pilot scale.

\subsubsection{Sequential coupling of combined system and photocatalysis}

Fig. 3 shows the dependence of abatement efficiency, carbon dioxide selectivity and ozone formation on the sequential order for coupling of plasma and photocatalysis. From this fi $\square$ re $\square$ it was found that the abatement efficiency using configuration (I) has been increased by $30 \%$ compared to configuration (II). The same behavior was seen with the selectivity of $\mathrm{CO}_{2}$. Results indicate also that switching the position of photocatalysis area strongly affect ozone decomposition. Indeed, when photocatalysis is introduced in post discharge, ozone outlet concentrations are reduced three times. Knowing that the photocatalytic reactor does not produce ozone, this behavior can be explained by the fact that produced ozone is decomposed when $\mathrm{UV}+\mathrm{TiO}_{2}$ was introduced into the post-combined system [12]. Since some studies show that the conversion of ozone under different conditions was $\mathrm{UV}+\mathrm{TiO}_{2}>\mathrm{TiO}_{2}>\mathrm{UV}[\mathbf{2 6}]$. Thus, in the $\mathrm{UV} / \mathrm{TiO}_{2}$ process, ozone is mainly consumed through three reactions: decomposition by the catalyst, decomposition by UV light and acting as a actives species (such as $\mathrm{O}^{\circ}$ and hydroxyl radial) scavenger. 
The scavenger role after ozone decompostion can explain the highest value of abatement efficiency and mineralization. Indeed, several mechanisms are occurring in configuration (I). Since the combined system produces various species such as high energy electrons, excited molecules or radicals $\left({ }^{\circ} \mathrm{O},{ }^{\circ} \mathrm{N}, \mathrm{OH}^{\circ}, \mathrm{NO}_{2}, \mathrm{NO}_{x}\right.$, etc.) $[13,30]$. These species have been trapped in post discharge area (photocatalysis zone) and can interact directly with BUTY molecules or its byproducts resulting in an enhancement of abatement efficiency and mineralization.

Fig. 3: Variation of RE, amount of ozone, $\mathrm{CO}_{2}$ selectivity with configurations I (50 \% coupled process $+50 \%$ photocatalyst $)$ and II (50\% photocatalyst $+50 \%$ coupled process) using planar reactor $\left(Q=10 \mathrm{~m}^{3} \mathrm{~h}^{-1},[B U T Y]=40 \mathrm{mg} \mathrm{m}^{-3}\right)$.

\subsubsection{Sequential coupling of plasma and combined system}

Results in fig. 4 indicate that the behavior of BUTY abatement efficiency, mineralization and ozone are similar to fig.3. In fact, when plasma DBD is introduced in post discharge, ozone outlet concentrations are less than $15 \%$ compared to fig.3. These results confirm the role of the photocatalysis on reactor performance. From the study of Taranto and co-workers [28] we can note that $\mathrm{TiO}_{2}$ introduced in plasma discharge with UV radiation can reduce ozone formation or favor its destruction by the following reaction $[\mathbf{8}, \mathbf{2 8}]$ :

$$
\begin{aligned}
& \mathrm{O}_{3}+\mathrm{e}^{-} \rightarrow{ }^{\bullet} \mathrm{O}^{-}+\mathrm{O}_{2} \\
& \text { or } \quad \mathrm{O}_{3}+\mathrm{hv}(254<\lambda<350 \mathrm{~nm}) \rightarrow \mathrm{O}_{2}+{ }^{\bullet} \mathrm{O}
\end{aligned}
$$

It is interesting to note that configuration (III) is slightly better than (IV) because the amount of ozone decomposed isn't important. This result further confirms the importance of o $\square$ one decomposition in plasma-photocatalytic effects.

Fig. 4: Variation of $\mathrm{RE}$, amount of ozone and $\mathrm{CO}_{2}$ selectivity with configurations III (50 $\%$ DBD plasma $+50 \%$ coupled process $)$ and IV (50\% coupled process $+50 \%$ plasma DBD) using planar reactor $\left(Q=10 \mathrm{~m}^{3} \mathrm{~h}^{-1},[B U T Y]=40 \mathrm{mg} \mathrm{m}^{-3}\right)$.

This scenario in which ozone is decomposed on the catalyst surface, thereby creating active species to oxidize adsorbed BUTY, is quite attractive for environmental applications and partly accounts for the synergy observed in different plasma-photocatalytic systems [29]. 
Synergetic effect has been reported to be due to enhancement of mass transfer in discharge zone which was near to photocatalyst media [21]. This study confirms that there is another reason which can explain the synergetic effect. Indeed, species like ${ }^{\circ} \mathrm{O}$ (due to ozone decomposition) and ${ }^{\circ} \mathrm{N}, \mathrm{OH}^{\circ}, \mathrm{NO}_{2}, \mathrm{NO}_{x}$, etc. have been trapped in photocatalysis zone and can interact directly with BUTY molecules or its byproducts resulting in an enhancement of the abatement efficiency and mineralization [13].

\section{Comparative study of energy consumption at pilot scale}

In order to investigate the performance of continuous and sequential combined processes between plasma and photocatalysis, the energy yield (EY) in units of the mass (in units of mg degraded) of BUTY removed per Wh input $\left(\mathrm{mg} . \mathrm{W}^{-1} \mathrm{~h}^{-1}\right)$ is calculated by using the formula:

- For plasma zone: $\quad \mathbf{E Y}_{\text {plasana }}=\left(\frac{Q\left([B U T Y]_{i \mathfrak{n}}-[B U T Y]_{\text {orut }}\right)}{P \times \varphi}\right)$

- For photocatalytic zone : $\mathbf{E Y}_{\text {photocatalysts }}=\left(\frac{Q\left([B U T Y]_{\text {in }}-[B U T Y]_{\text {out }}\right)}{N \times P_{\text {tamp }}}\right)$

where $\mathrm{P}$ is the power consumption in plasma zone (W), $\square \mathrm{i} \square \square \square[\mathrm{i} \square \| \square \square \mathrm{m} \square \mathrm{i} \square \mathrm{i} \square \square \square \square \square \square \square$ it equal to $15 \%$, $I$ is the intensity of $U V \operatorname{lamp}\left(\mathrm{W} \mathrm{m}^{-2}\right), \mathrm{N}$ is number of lamps used, $\mathrm{P}_{\text {lamp }}$ is the real power consumption of one $\mathrm{UV}$ lamp. $E Y_{\text {plasma }}$ and $E Y_{\text {photocatalysis }}$ are respectively the energy yield in plasma and photocatalytic zone.

Fig. 5 shows the comparison of energetic performance at different configurations in terms of removal efficiency and energy yield. We note that when the plasma area increases in the reactor, we need more energy to degrade the BUTY. In fact, for the reactor with $100 \%$ combined system, EY was higher than that with $100 \%$ plasma and the others configurations (I, II, III and IV). Additionally, it was found that the combined system is the interesting configuration because at same EY, the removal efficiency with combined system is higher than for all the configurations. This behavior can be due to the fact that some interaction occurs between plasma and photocatalysis. This can be another reason of synergetic effect.

Fig. 5: Variation of removal efficiency and energy yield vs the different configurations of tested processes using planar reactor $\left(Q=10 \mathrm{~m}^{3} \mathrm{~h}^{-1},[B U T Y]=40 \mathrm{mg} \mathrm{m}^{-3}\right)$. 


\section{Conclusion}

This work focuses on two parts: firstly the abatement of butyraldehyde has been investigated by continuous combined process including DBD plasma and heterogeneous photocatalysis. The synergy due to processes combination has been confirmed

On the other hand, some sequential coupling processes have been tested at pilot scale. The main findin $\square$ s of this second investigation can be summarized as follows:

1) It has been clearly demonstrated that the combination of photocatalysis in the post-plasma not only dramatically enhanced the conversion of BUTY, but also effectively improved the mineralization. Almost more than $60 \%$ of ozone was destructed in the system. Moreover, photocatalytic reactor is the most economic configuration in term of energy consumption.

2) On the contrary, when photocatalysis takes place in the first part, the activity of photocatalyst is less important than when it is placed in the second part of reactor.

3) The second reason of the synergetic effect can be due to ozone decomposition by photocatalyst which leads to increase the amount of actives species. In fact, these species have been trapped in photocatalysis zone and can interact directly with BUTY molecules or its byproducts resulting in an enhancement abatement efficiency and mineralization.

\section{Acknowledgment}

The authors wish to thank the French National Research Agency (ANR) for supporting this research. They also thank the Ahlstrom Company for providing the photocatalytic medium.

\section{References}


[1] G.R. Parmar, N.N. Rao, Emerging Control Technologies for Volatile Organic Compounds. Crit. Rev. Env. Sci. Technol. 39 (2009) 41-78.

[2] H. J. Bloemen, J. Burn, Chemistry and Analysis of Volatile Organic Compounds in the Environment, Springer, London, 2012.

[3] Council of Europe Directive 1999/13/EC on the limitation of emissions of volatile organic compounds due to use of organic solvents in certain activities and installations, Official Journal of the European Union, 1999, $L 85,1$.

[4] A. M. Vandenbroucke, R. Morent, N. De Geyter, Ch. Leys, Non-thermal plasmas for non-catalytic and catalytic VOC abatement, Journal of Hazardous Materials 195 (2011) 30-54

[5] Chang C-L, Lin T-S Decomposition of toluene and acetone in packed dielectric barrier discharge reactors. Plasma Chem Plasma Process 25 (2005) 227-243.

[6] A. A. Assadi, A. Bouzaza, M. Lemasle, D. Wolbert, Removal of trimethylamine and isovaleric acid from gas streams in a continuous flow surface discharge plasma reactor, Chemical Engineering Research and Design 93 (2015) 640-651

[7] M.P. Cal, M. Schluep, Destruction of Benzene with Non-Thermal Plasma in Dielectric Barrier Discharge Reactors, Environ. Prog. 20 (2001) 151-156.

[8] Guaitella $\mathrm{O}$, Thevenet F, Puzenat E, Guillard C, Rousseau A, $\mathrm{C}_{2} \mathrm{H}_{2}$ oxidation by plasma/ $\mathrm{TiO}_{2}$ combination: Influence of the porosity, and photocatalytic mechanisms under plasma exposure. Applied Catalysis B: Environmental 80 (2008) 296-305.

[9] Debono O, Thevenet F, Gravejat P, Hequet V, Raillard, C, Lecoq L, Locoge N Toluene photocatalytic oxidation at ppbv levels: Kinetic investigation and carbon balance determination. Applied Catalysis B: Environmental 106 (2011) 600-608.

[10] Futamura S, Einaga H, Kabashima H, Hwan LY, Synergistic effect of silent discharge plasma and catalysts on benzene decomposition. Catal Today 89 (2004) 89-95.

[11] A. A. Assadi, A. Bouzaza, C.Vallet, D. Wolbert, Use of DBD plasma, photocatalysis, and combined DBD plasma/photocatalysis in a continuous annular reactor for isovaleraldehyde elimination - Synergetic effect and byproducts identification, Chemical Engineering Journal 254 (2014) 124-132.

[12] F Thevenet, O Guaitella, E Puzenat, C Guillard, A Rousseau, Influence of water vapour on plasma/photocatalytic oxidation efficiency of acetylene. Appl Catal B Environ 84 (2012) 813-820 
[13] Thevenet F., Sivachandiran L., Guaitella O., Barakat C., Rousseau A.: Plasma-catalyst coupling for volatile organic compound removal and indoor air treatment: a review. J. Phys. D: Appl. Phys. 47 (2014) 224011-224022

[14] International Programme on Chemical Safety (IPCS), OECD screening information databases 3-methyl butanal. UNEP, Canadian Centre for Occupational Health and Safety (CCOHS), 2004.

[15] ADEME, Pollutions olfactives : origine, législation, analyse, traitement. Ademe, Dunod, Angers, 2005.

[16] T.C. Manley,Proceedings of the 84th General Meeting, New York, 1943.

[17] R. Atkinson, D. L. Baulch, R. A. Cox, J. N. Crowley, R. F. Hampson, R. G. Hynes, M. E. Jenkin, M. J. Rossi, J. Troe, Evaluated kinetic and photochemical data for atmospheric chemistry: Part 1 - gas phase reactions of $\mathrm{O}_{x}, \mathrm{HO}_{x}, \mathrm{NO}_{\mathrm{x}}$ and $\mathrm{SO}_{\mathrm{x}}$ species. Atmospheric chemistry and Physics Discussions 3 (2003) 6179-6699.

[18] F. Thevenet, C. Guillard, A. Rousseau, Acetylene photocatalytic oxidation using continuous flow reactor Gas phase and adsorbed phase investigation, assessment of the photocatalyst deactivation, Chemical Engineering Journal 244 (2014) 50-58

[19] A. A. Assadi, A.Bouzaza, D. Wolbert, Photocatalytic oxidation of trimethylamine and isovaleraldehyde in an annular reactor: Influence of the mass transfer and the relati $\sqsubset$ e humidit $\square$ Journal of $\square$ hotochemistr $\square$ and Photobiology A: Chemistry 236 (2012) 61-69.

[20] M. Guillerm, A.A.Assadi , A. Bouzaza, D. Wolbert, Removal of gas-phase ammonia and hydrogen sulfide using photocatalysis, nonthermal plasma, and combined plasma and photocatalysis at pilot scale, Environmental Science and Pollution Research 21 (2014) 13127-13137

[21] A. A. Assadi, A.Bouzaza, S. Merabet, D. Wolbert, Modeling and simulation of VOCs removal by nonthermal plasma discharge with photocatalysis in a continuous reactor: Synergetic effect and mass transfer, Chemical Engineering Journal 258 (2014) 119-127.

[22] A.A. Assadi, A. Bouzaza, D. Wolbert, P. Petit, Isovaleraldehyde elimination by $\mathrm{UV} / \mathrm{TiO}_{2}$ photocatalysis: comparative study of the process at different reactors configurations and scales, Environmental Science and Pollution Research 21 (2014) 11178-11188.

[23] J. Chen, Zh. Xie, Removal of $\mathrm{H}_{2} \mathrm{~S}$ in a novel dielectric barrier discharge reactor with photocatalytic electrode and activated carbon fiber. Journal of Hazardous Materials 261 (2013) 38-43

[24] W. Liang, L. Ma, H. Liu, J. Li, Toluene degradation by non-thermal plasma combined with a ferroelectric catalyst, Chemosphere 92 (2013) 1390-1395

[25] H. Q. Trinh, Y. S. Mok, Plasma-catalytic oxidation of acetone in annular porous monolithic ceramicsupported catalysts, Chemical Engineering Journal 251 (2014) 199-206. 
[26] A. Ogata, K. Saito, H-H Kim, M. Sugasawa, H. Aritani, H. Einaga, Performance of an Ozone Decomposition Catalyst in Hybrid Plasma Reactors for Volatile Organic Compound Removal, Plasma Chem Plasma Process (2010) 30:33-42.

[?2 ?]J.Karuppiah, E. L. Reddy, P.M. K. Reddy, B.Ramaraju, ,R. Karvembu, Ch. Subrahmanyama. Abatement of mixture of volatile organic compounds (VOCs) in a catalytic non-thermal plasma reactor. Journal of Hazardous Materials 237-238 (2012) 283-289.

[28] J. Taranto, D. Frochot, P. Pichat, Combining Cold Plasma and $\mathrm{TiO}_{2}$ Photocatalysis To Purify Gaseous Effluents: A Preliminary Study Using Methanol-Contaminated Air, Ind. Eng. Chem. Res. 46 (2007) 7611-7614.

[29] Y. Li, Z. Fan, J.Shi, Zh.Liu, W. Shangguan, Post plasma-catalysis for VOCs degradation over different phase structure $\mathrm{MnO}_{2}$ catalysts, Chemical Engineering Journal 241 (2014) 251-258.

[30] J. Palau, A.A. Assadi, J.M. Penya-roja, A. Bouzaza, D. Wolbert, V. Martínez-Soria, Isovaleraldehyde degradation using UV photocatalytic and dielectric barrier discharge reactors, and their combinations 299 (2015) $110-117$.

\section{Figures:}

Fig 1: Experimental set-up

Fig. 2: Relationship between the selectivity of $\mathrm{CO}_{2}$ and the removal efficiency for the plasma, photocatalysis and combined system at different flowrates and inlet concentration.

Fig. 3: Variation of $\mathrm{RE}$, amount of ozone, $\mathrm{CO}_{2}$ selectivity with configurations I (50\% coupled process $+50 \%$ photocatalyst $)$ and II (50\% photocatalyst $+50 \%$ coupled process $)$ using planar reactor $\left(\mathrm{Q}=10 \mathrm{~m}^{3} \mathrm{~h}^{-1},[\mathrm{BUTY}]=40 \mathrm{mg} \mathrm{m}^{-3}\right)$.

Fig. 4: Variation of $\mathrm{RE}$, amount of ozone and $\mathrm{CO}_{2}$ selectivity with configurations III (50\% DBD plasma $+50 \%$ coupled process $)$ and IV (50\% coupled process $+50 \%$ plasma DBD) using planar reactor $\left(\mathrm{Q}=10 \mathrm{~m}^{3} \mathrm{~h}^{-1},[\mathrm{BUTY}]=40 \mathrm{mg} \mathrm{m}^{-3}\right)$.

Fig. 5: Variation of removal efficiency and energy yield vs the different configurations of tested processes using planar reactor $\left(\mathrm{Q}=10 \mathrm{~m}^{3} \mathrm{~h}^{-1}\right.$, $\left.[\mathrm{BUTY}]=40 \mathrm{mg} \mathrm{m}^{-3}\right)$. 


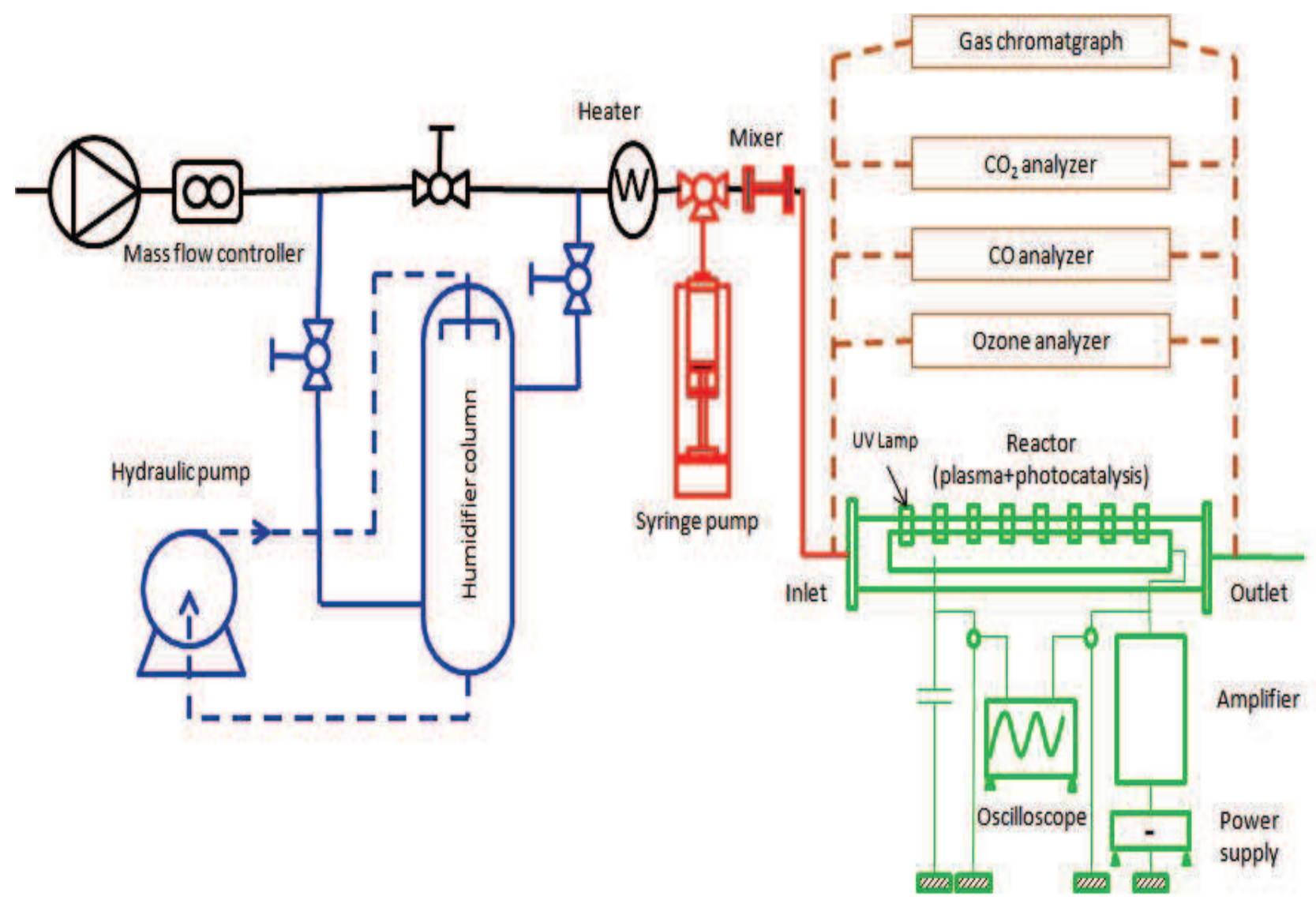

Fig. 1 


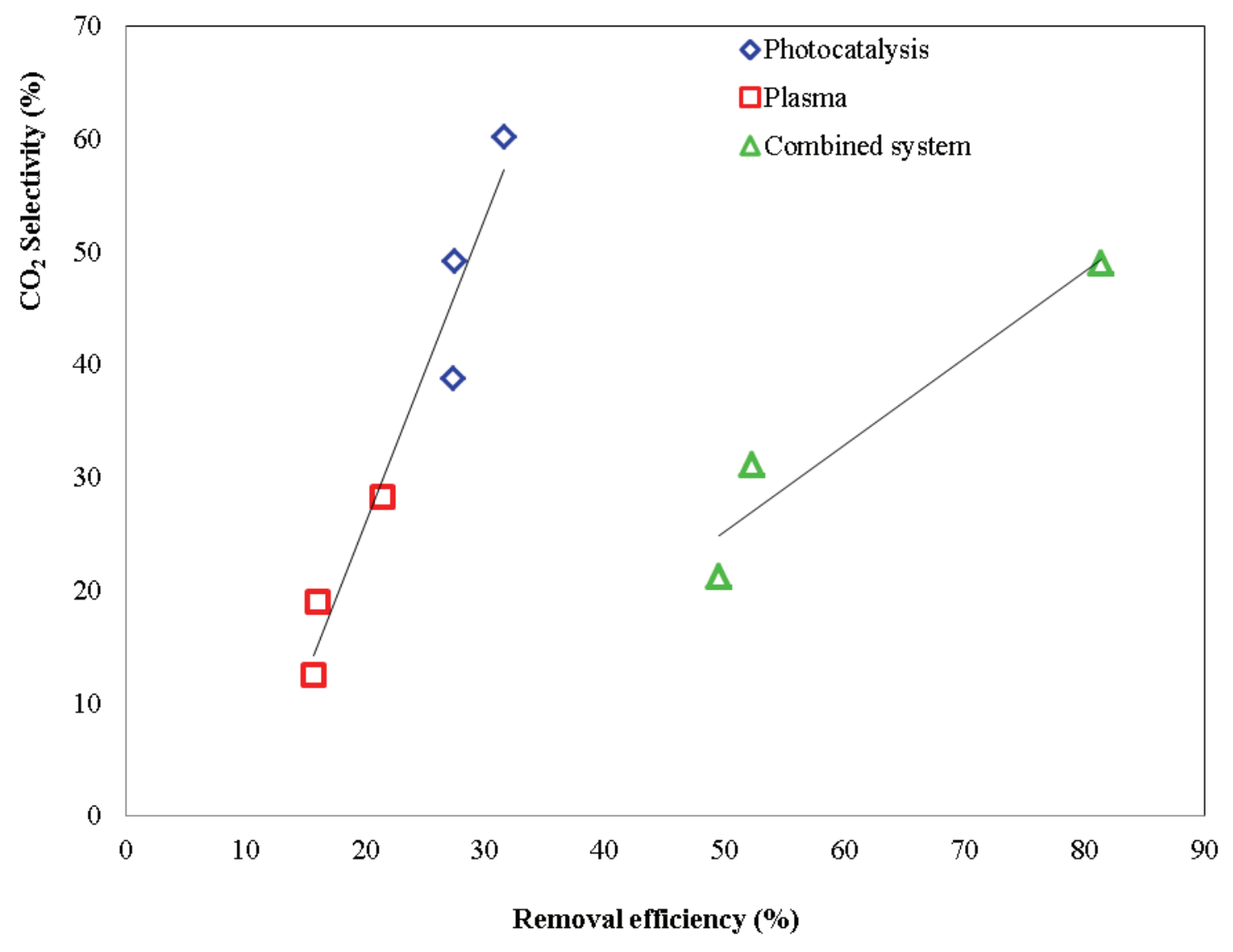

Fig. 2 


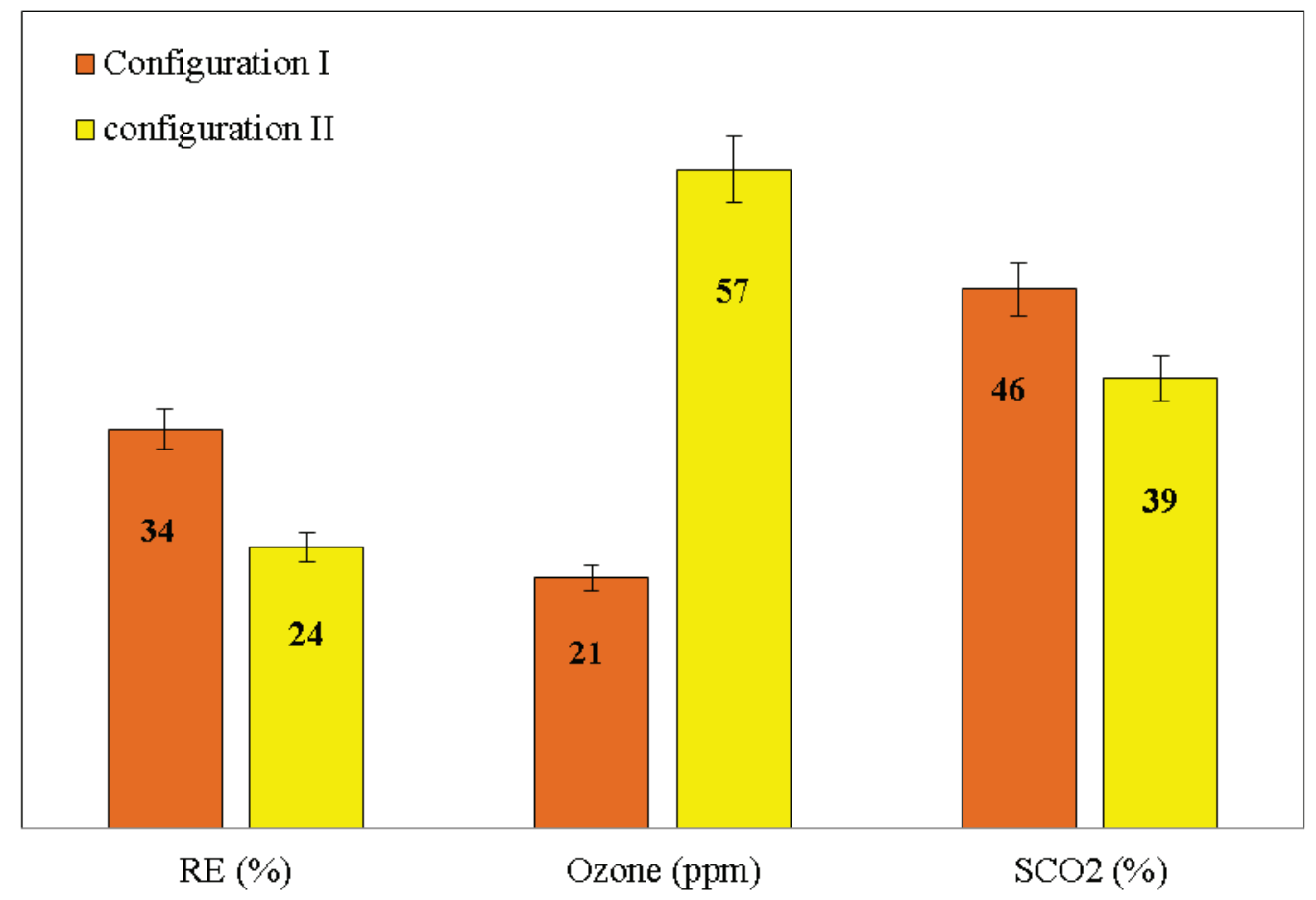

Fig. 3

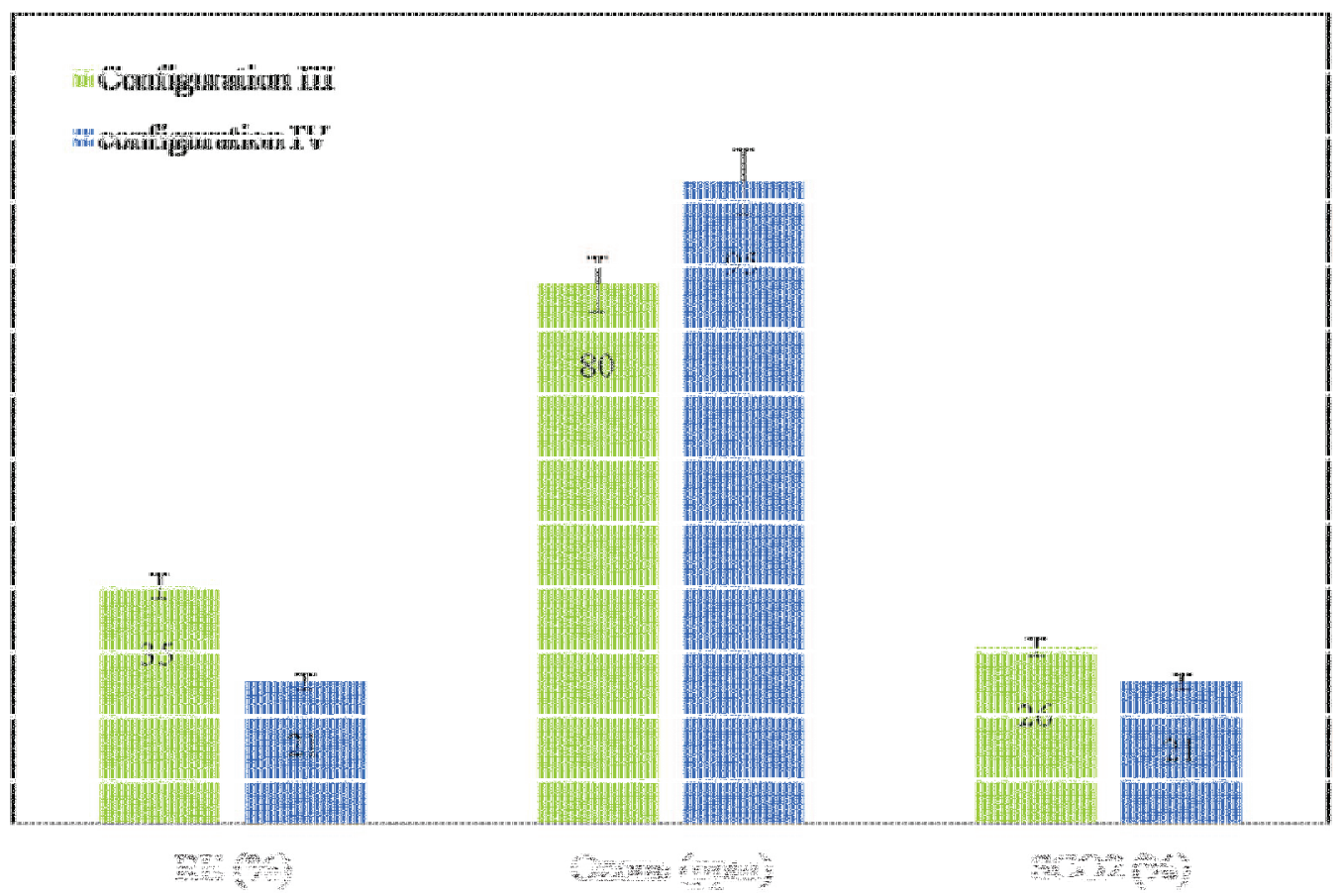

Fig. 4 


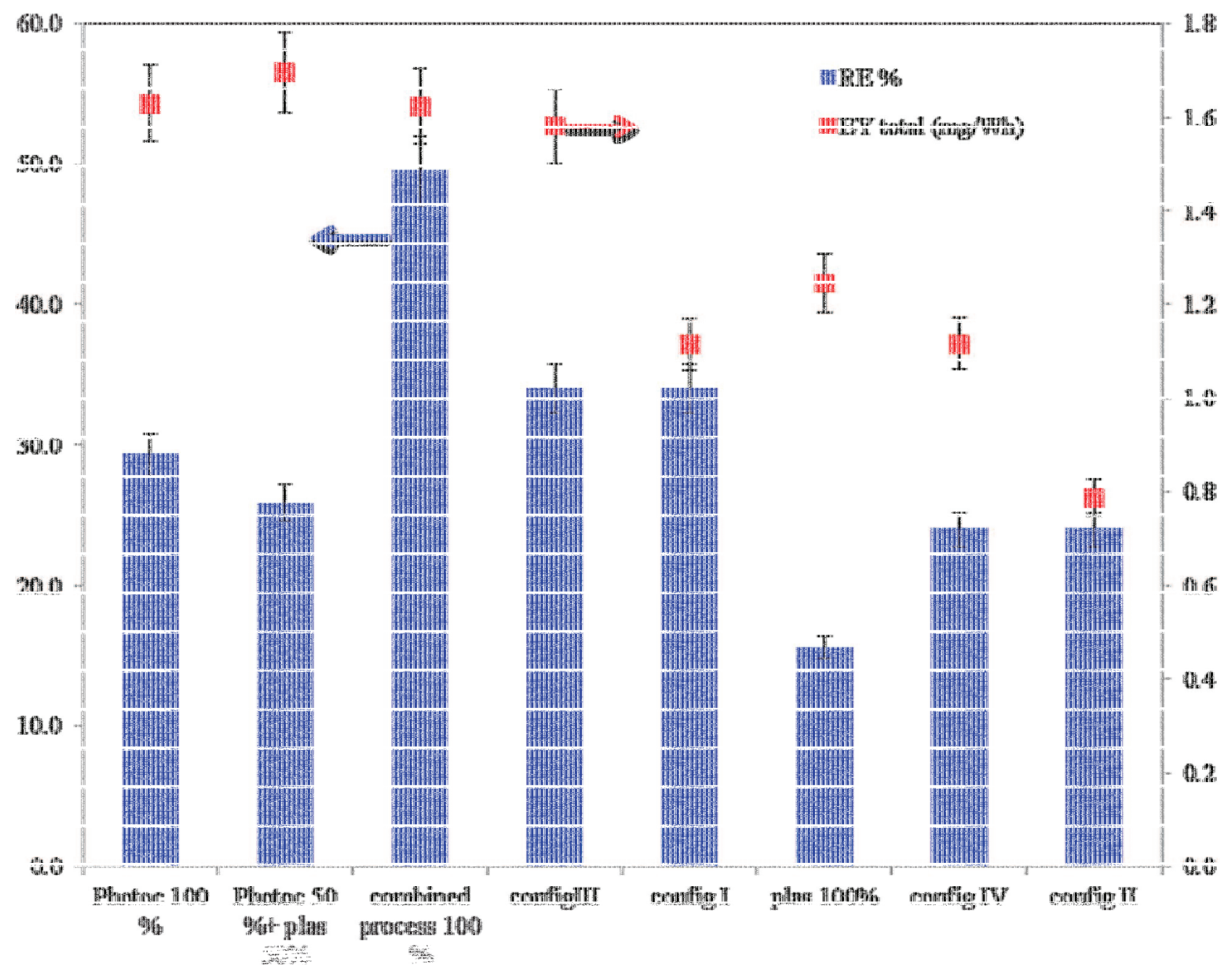

Fig. 5 


\section{Tables}

Table 1: $\mathrm{CO}_{2}$ Selectivity and residual ozone concentration at the exit of the reactor for different tested configurations (room temperature, input energy density $=14 \mathrm{~J} \mathrm{~L}^{-1}$ ).

Table 2: EC values $\left(\mathrm{mg} \mathrm{h}^{-1}\right)$ for BUTY removal by DBD plasma, photocatalysis and a combined process at different flowrate and inlet concentration $\left(\mathrm{SE}=14 \mathrm{~J} \mathrm{~L}^{-1}, \mathrm{~T}=20{ }^{\circ} \mathrm{C}\right.$, $\left.\mathrm{I}=20 \mathrm{Wm}^{-2}\right)$.

Table 1: $\mathrm{CO}_{2}$ Selectivity and residual ozone concentration at the exit of the reactor for different tested configurations (room temperature, plasma energy density $=14 \mathrm{~J} \mathrm{~L}^{-1}$ ).

\begin{tabular}{|c|c|c|c|c|}
\cline { 2 - 5 } \multicolumn{1}{c|}{} & $\mathrm{Q}\left(\mathrm{m}^{3} \mathrm{~h}^{-1}\right)$ & $\begin{array}{c}{[\mathrm{BUTY}]} \\
\left(\mathrm{mg} \mathrm{m}^{-3}\right)\end{array}$ & $\begin{array}{c}\mathrm{CO}_{2} \text { Selectivities } \\
(\%)\end{array}$ & $\begin{array}{c}\text { Residual } \mathrm{O}_{3} \\
(\mathrm{ppm})\end{array}$ \\
\hline \multirow{4}{*}{$\begin{array}{c}\text { Photocatalysis } \\
\text { alone }\end{array}$} & 5 & 40 & 60.2 & $<=0.1$ \\
\cline { 2 - 5 } & 5 & 100 & 49.1 & $<=0.1$ \\
\cline { 2 - 5 } & 10 & 100 & 38.8 & 109.7 \\
\cline { 2 - 5 } & 5 & 40 & 28.2 & 83.2 \\
\cline { 2 - 5 } & 10 & 100 & 18.9 & 89.2 \\
\hline \multirow{3}{*}{$\begin{array}{c}\text { Plasma alone } \\
\text { Combined }\end{array}$} & 5 & 40 & 48.9 & 70.4 \\
\cline { 2 - 5 } & 5 & 100 & 31.0 & 91.0 \\
\cline { 2 - 5 } & 10 & 100 & 21.2 & 88.6 \\
\hline
\end{tabular}


Table 2: EC values $\left(\mathrm{mg} \mathrm{h}^{-1}\right)$ for BUTY removal by DBD plasma, photocatalysis and a combined process at different flowrate and inlet concentration $\left(\mathrm{SE}=14 \mathrm{~J} \mathrm{~L}^{-1}, \mathrm{~T}=20^{\circ} \mathrm{C}\right.$, $\left.\mathbf{I}=20 \mathrm{Wm}^{-2}\right)$.

\begin{tabular}{|c|c|c|c|}
\hline Process & $\begin{array}{c}\mathrm{Q}=5 \mathrm{~m}^{3} \mathrm{~h}^{-1} \\
{[\mathrm{BUTY}]=40 \mathrm{mg} \mathrm{m}^{-3}}\end{array}$ & $\begin{array}{c}\mathrm{Q}=5 \mathrm{~m}^{3} \mathrm{~h}^{-1} \\
{[\mathrm{BUTY}]=100 \mathrm{mg} \mathrm{m}^{-3}}\end{array}$ & $\begin{array}{c}\mathrm{Q}=10 \mathrm{~m}^{3} \mathrm{~h}^{-1} \\
{[\mathrm{BUTY}]=100 \mathrm{mg} \mathrm{m}^{-3}}\end{array}$ \\
\hline Plasma alone & 42.86 & 80.35 & 155.70 \\
\hline Photocatalysis alone & 63.20 & 136.9 & 273.10 \\
\hline Combined system & 126.90 & 261.40 & 495.20 \\
\hline
\end{tabular}

